\title{
BIOMASSA E NUTRIENTES EM Myrsine ferruginea (Ruiz \& Pav.) Mez E Myrsine umbellata Mart
}

\author{
Marcos Vinicius Winckler Caldeira ${ }^{1}$ \\ Ronaldo Viana Soares ${ }^{2}$ \\ Renato Marques ${ }^{3}$ \\ Celina Wisniewski ${ }^{3}$
}

\begin{abstract}
RESUMO
Este estudo teve como objetivo quantificar a biomassa acima do solo e o conteúdo de macronutientes de duas espécies arbóreas (Myrsine ferruginea e Myrsine umbellata) da Floresta Ombrófila Mista Montana. Os dados foram coletados em 10 árvores de M. ferruginea e 9 árvores de M. umbellata, extraídas de 20 parcelas de $12 \mathrm{~m}$ x $12 \mathrm{~m}$. A maior produção de biomassa total e de cada componente foi verificada em $M$. ferruginea, exceto a produção de folhas que foi maior em M. umbellata; os maiores conteúdos de macronutrientes na biomassa total também foram verificados em M. ferruginea.

Palavra chave: Biomassa, Floresta com Araucária, Sustentabilidade, Produtividade
\end{abstract}

BIOMASS AND NUTRIENT IN Myrsine ferruginea (Ruiz \& Pav.) Mez E Myrsine umbellata Mart

\begin{abstract}
The objective of this research was to quantify the above-ground biomass and macronutrient contents of two forest species (Myrsine ferruginea and Myrsine umbellata) found in the Ombrofila Mix Montana Forest. Data were collected from 10 trees of $M$. ferruginea and 9 trees of $M$. umbellata extracted from $12 \mathrm{~m} \times 12 \mathrm{~m}$ experimental plots. The highest biomass production was found in $M$. ferruginea, except foliage that was higher in M. umbellata. The highest macronutrient accumulation were also observed in M. ferruginea.
\end{abstract}

Key-words: Biomass, Nutrients, Mixed Araucaria Forest, Productivity

\section{INTRODUÇÃO}

A quantificação da biomassa fornece informações sobre a magnitude, a qualidade e a distribuição dos produtos da floresta que não se encontram nos tradicionais mapas dos ecossistemas. Seu conhecimento também é importante do ponto de vista ecológico, porque permite estabelecer a produção real de um sítio florestal ou das espécies (Caldentey, 1995), e conhecer o crescimento, a produtividade e o ciclo dos nutrientes nos ecossistemas florestais tanto naturais como implantados (Luy, Goya; Frangi, 1997).

O aumento na produção de biomassa depende, em última instância, do potencial genético de cada espécie em fixar carbono e absorver água e nutrientes, como também de fatores como doenças, pragas, competição e idade. Assim, altas produtividades podem ser obtidas com o uso de material genético superior e com a otimização do uso dos fatores ambientais, especialmente água e nutriente, por meio de práticas de manejo aplicadas à floresta (Silva, 1990).

O conhecimento sobre o teor, bem como a distribuição dos nutrientes nas espécies é fundamental para estabelecer estratégias de amostragem com a finalidade de estudar a nutrição, ciclagem e exportação (Caldeira, 1998). A determinação do teor de nutrientes nos componentes das árvores, segundo Montagnini e Sancho (1994), juntamente com a determinação de biomassa, podem ser utilizadas como indicadores dos impactos ambientais potenciais das árvores e da colheita florestal sobre os nutrientes no sítio, permitindo, assim, segundo Drumond et al.

\footnotetext{
${ }^{1}$ Eng. Florestal, Dr. Prof ${ }^{\text {. }}$ Centro de Ciências Tecnológicas/Depto de Eng. Florestal/FURBcaldeira@,furb.br

${ }^{2}$ Dr. Prof ${ }^{\mathrm{o}}$ do Departamento de Ciências Florestais, Centro de Ciências Florestais e da Madeira/UFPR

${ }^{3}$ Dr. Prof ${ }^{\mathrm{o}}$ do Departamento de Solos e Eng ${ }^{\mathrm{o}}$ Agrícola, Setor de Ciências Agrárias/UFPR
} 
(1997b), adoção de estratégias de manejo que levam à redução da perda de nutrientes.

Ainda existem poucas informações sobre a autoecologia, o crescimento e o processo silvicultural, bem como sobre o teor de nutrientes e a produção de biomassa de $M$. ferruginea e M. umbellata.

Este trabalho teve como objetivo estimar a produção de biomassa e o conteúdo de macronutrientes de duas espécies arbóreas (M. ferruginea e M. umbellata) comumente conhecidas como capororoquinha e capororoca em uma Floresta Ombrófila Mista Montana de General Carneiro, Paraná.

Figura 1: Localização do município de General Carneiro Figure 1: Location in the General Carneiro

\section{MATERIAIS E MÉTODOS}

$\mathrm{O}$ presente estudo foi realizado em uma propriedade das Indústrias Pedro $\mathrm{N}$. Pizzatto, localizada no município de General Carneiro, Paraná, que fica no extremo sul do estado, fazendo divisa com o Estado de Santa Catarina (fig. 1). General Carneiro está localizado na interseção das coordenadas geográficas $26^{\circ} 43^{\prime} 00^{\prime \prime}$ latitude $\mathrm{S}$ e $51^{\circ} 24^{\prime}$ 35 " longitude $\mathrm{W}$ de Greenwich, com altitude aproximada de $1000 \mathrm{~m}$ s.n.m. (PARANÁ, 1987). A área da fazenda onde foi desenvolvido o trabalho é de aproximadamente de 4.570 ha.

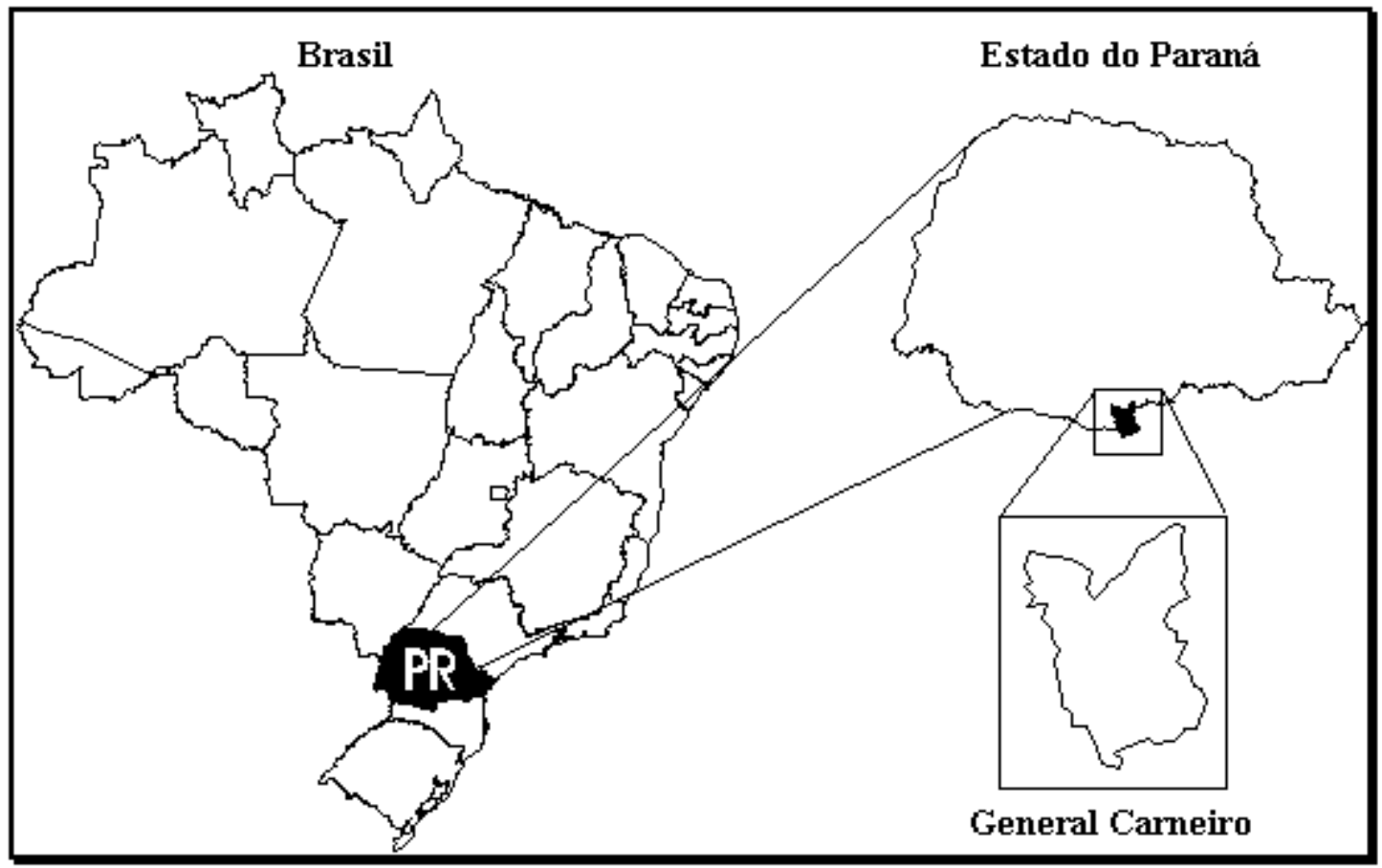

Pela classificação de Köeppen, o clima da região é caracterizado como Subtropical Úmido Mesotérmico ( $\mathrm{Cfb}$ ), ou seja, temperado com verões frescos e invernos com ocorrência de geadas severas, sem estação seca. A média das temperaturas do mês mais quente é inferior a $22^{\circ} \mathrm{C}$ e a do mês mais frio é superior a $-18^{\circ} \mathrm{C}$ (PARANÁ, 1987; IAPAR, 1994).

Nesta região, pelo sistema de classificação de solos da EMBRAPA (1999) os tipos de solos predominantes são os Neossolos Litólicos, Cambissolos (BOLETIM DE
PESQUISA, 1984) e Argissolos (PARANÁ, 1987).

Conforme a classificação do IBGE (1992), a formação florestal original da área de estudo é classificada como Floresta Ombrófila Mista Montana. Contudo, devido às diversas atividades antrópicas a vegetação se encontra em diferentes estágios sucessionais.

$\mathrm{Na}$ figura 2 pode-se observar a distribuição dos tipos vegetacionais existentes na área de estudo, com as respectivas localizações das parcelas utilizadas no presente trabalho. 
Figura 2: Interpretação visual do uso do solo e localização das unidades amostrais nas Indústrias Pedro N. Pizzatto, General Carneiro

Figure 2: Soil occupation and experimental plots location in the Pedro N. Pizzato Co. forest district. General Carneiro

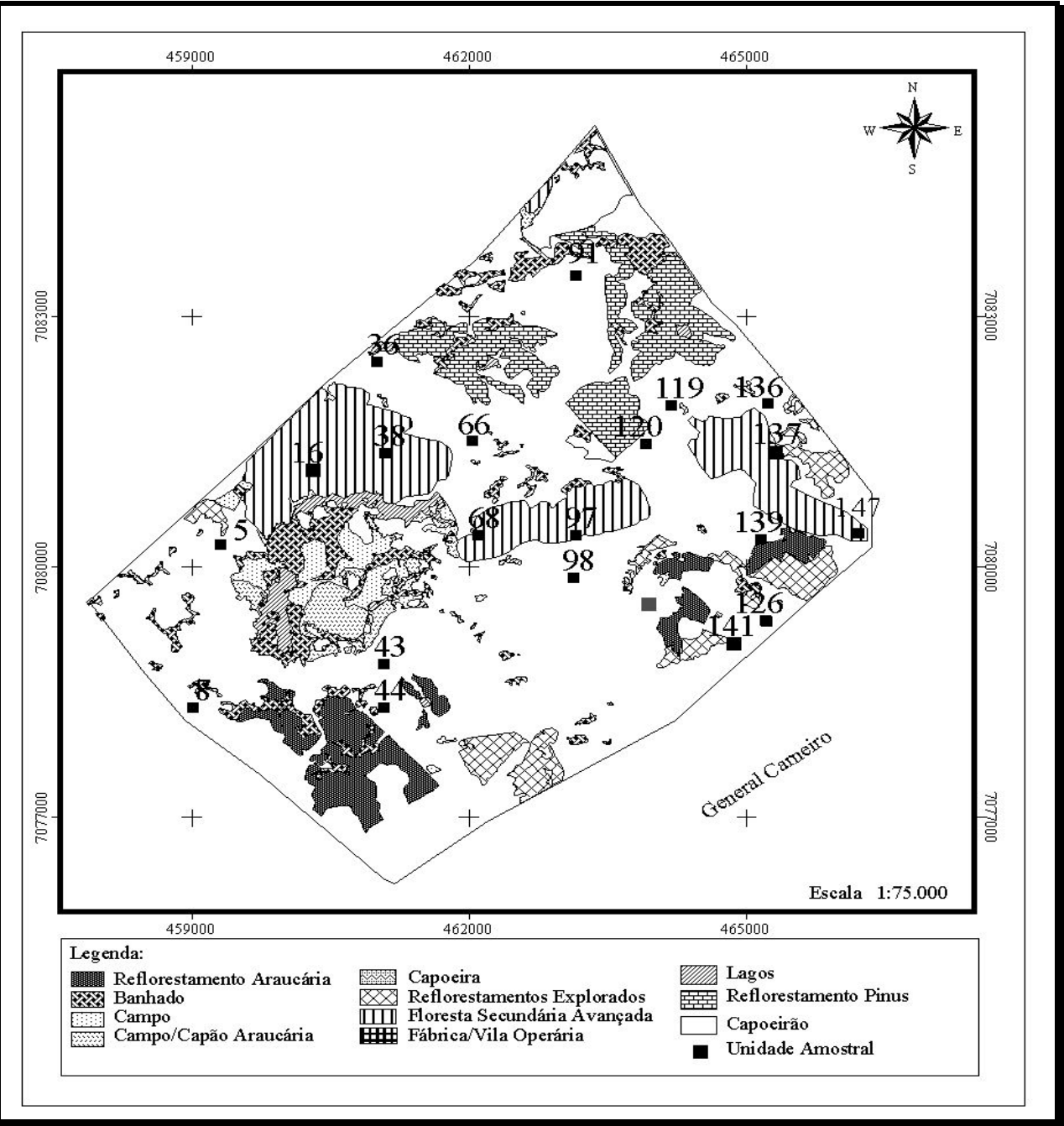

Fonte: Universidade Federal do Paraná, Setor de Ciências Agrárias. Laboratório de Inventário Florestal. Análise visual do uso da terra utilizando imagem do satélite de alta resolução IKONOS II. Curitiba, 2002. (Não publicado).

No primeiro semestre de 2001, o Laboratório de Inventário Florestal/UFPR realizou inventário florestal, utilizando o método de amostragem de área fixa e o processo sistemático, no qual foram locadas e medidas 70 unidades amostrais (UAs) de $25 \mathrm{~m}$ x $100 \mathrm{~m}$, numeradas de 1 a 70 .

Destas 70 UAs, conforme Watzlawick [200-] foram sorteadas aleatoriamente 20 para a quantificação de biomassa do presente estudo. Nestas, foram locadas subunidades amostrais de $12 \mathrm{~m}$ x $12 \mathrm{~m}$ (unidade amostral primária - UAP) com orientação Norte-Sul. Dentro de cada UAP, foram locadas três subunidades amostrais transversalmente de 1 $\mathrm{m} \times 1 \mathrm{~m}$ (unidade amostral secundária - UAS), dispostas no canto inferior, centro e canto superior (fig. 3). 
Figura 3: Esquema da instalação das unidades amostrais

Figure 3: Experimental plots installation scheme

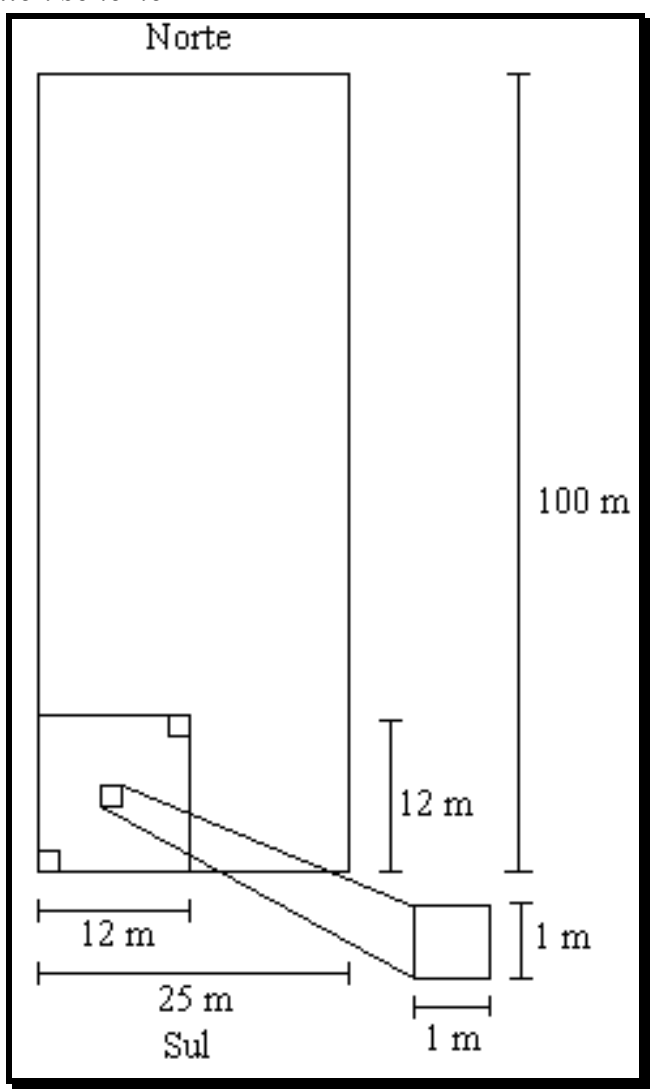

A quantificação de biomassa acima do solo (DAP $\geq 10,0 \mathrm{~cm}$ ), foi baseada na metodologia proposta por Watzlawick [200-]. A coleta foi realizada durante o primeiro semestre de 2001 (janeiro a julho).

Nas UAPs foram cortadas e medidas todas as árvores com DAP $\geq 10,0 \mathrm{~cm}$ para a determinação de biomassa acima do solo. De cada árvore foram medidas ou pesadas as seguintes variáveis: CAP (circunferência à altura do peito); altura total; altura comercial (ponto de inversão morfológica); comprimento, largura e espessura da casca; peso verde da casca, da madeira do fuste, das folhas, dos galhos e da miscelânea (musgos, liquens, lianas, bromélias, orquídeas). Durante a coleta foram quantificados também flores e frutos, mas devido ao material ser pouco, não possuindo muitas vezes amostras suficientes para as análises de macronutrientes, eles foram agrupados no componente miscelânea.

Os materiais coletados em cada UAP foram pesados separadamente no campo em uma balança. Depois de pesado cada componente da árvore (madeira do fuste, casca, galhos, folhas e miscelâneas) foram retiradas amostras de aproximadamente 300 gramas. Para a amostra de madeira do fuste foram retirados dois discos de aproximadamente $5,0 \mathrm{~cm}$ de espessura. O primeiro a $0,5 \mathrm{~m}$ de altura acima do corte da árvore e o segundo a $0,5 \mathrm{~m}$ abaixo do ponto de inversão morfológico. Para a amostra de casca foram utilizados os mesmos discos da amostra de madeira do fuste. Em cada disco amostrado foi separada a casca. A biomassa total de casca foi estimada utilizando relações de fator de casca. Somente foram considerados como galhos, aqueles que estavam acima do ponto de inversão morfológico. Para os galhos foram retiradas amostras em todos os diâmetros e em todas as alturas de copa. No que se refere às folhas, foram retiradas amostras na parte superior, intermediária e inferior da copa.

As amostras de cada componente foram acondicionadas em sacos de papel pardo, devidamente identificados para posteriormente serem levadas ao laboratório. 
No laboratório, as amostras foram colocadas em estufa de circulação e renovação de ar forçada, para secagem à temperatura de $75^{\circ} \mathrm{C}$ por um período de 72 horas, para a determinação da massa seca. Em seguida as mesmas foram trituradas em moinho do tipo Wiley, passadas em peneiras de malha $1,0 \mathrm{~mm}$ (20 mesh) e armazenadas em frascos de vidros para subseqüente análise química (Miyazawa et al., 1999).

Todos os indivíduos amostrados no estudo, ou seja, dez árvores para M. ferruginea e nove árvores para $M$. umbellata tiveram seu material vegetativo coletado e quando possível material reprodutivo, para serem submetidos aos processos de herborização, conforme recomendações do IBGE (1992). O material herborizado foi identificado no Laboratório de Inventário Florestal do Departamento de Ciências Florestais da Universidade Federal do Paraná.

Das espécies amostradas foram selecionadas três árvores com maior, médio e menor DAP para a determinação do teor dos macronutrientes nos componentes da biomassa. Para a determinação dos macronutrientes na casca e na madeira do fuste foi utilizada a média de duas amostras.

As análises químicas de tecido vegetal de $\mathrm{N}, \mathrm{P}, \mathrm{S}, \mathrm{K}, \mathrm{Ca}$ e $\mathrm{Mg}$ foram determinadas por digestão úmida. As análises de $\mathrm{N}$ foram feitas por titulação. $\mathrm{O} \mathrm{N}$ foi determinado pelo método Kjeldahl, também chamado de digestão sulfúrica, usando o destilador de nitrogênio. As amostras de $\mathrm{K}$ foram lidas no fotômetro de chama. As amostras de P e S foram lidas no espectrofotômetro UV-VIS. No espectrofotômetro de absorção atômica (EAA) foram lidas as amostras de $\mathrm{Ca}$ e $\mathrm{Mg}$ (Tedesco et al., 1995; Miyazawa et al., 1999).

A determinação da biomassa por espécie e por componente foi realizada através da soma das 10 árvores de $M$. ferruginea e das 9 árvores de M. umbellata e a biomassa por hectare foi calculada a partir da biomassa média das UAPs.

A quantidade dos nutrientes em kg.espécie-1 nos componentes da biomassa foi calculada através da multiplicação da biomassa (kg.espécie-1) pelo teor de nutrientes determinado para cada componente (madeira do fuste, casca, galhos, folhas e miscelânea).

\section{RESULTADOS E DISCUSSÃO}

\section{Biomassa e Distribuição Relativa dos Componentes}

As duas espécies estudadas, de uma maneira geral, apresentaram uma produção de biomassa diferenciada para todos os componentes analisados, apesar de não existir diferença pelo teste $t$ de Student $(p>0,05)$ na produção de biomassa de cada componente em cada espécie. A produção total de biomassa das dez árvores amostradas de $M$. ferruginea foi superior à das nove árvores amostradas de M. umbellata. A maior diferença na produção de biomassa entre as espécies foi no material lenhoso, seguido da biomassa total, galhos e madeira do fuste. A produção de biomassa de folhas foi similar nas duas espécies estudadas (tab. 1).

Observa-se na tabela 1 que a produção de biomassa de galhos, bem como a redistribuição relativa desse componente nas duas espécies foi superior à de madeira do fuste. Esse fato deve-se ao porte das árvores e à metodologia utilizada, onde foram considerados como galhos, aqueles que estavam acima do ponto de inversão morfológico e galhos epicórmicos abaixo do ponto. Essa constatação também foi observada no estudo de DRUMOND (1998) com Mimosa tenuiflora, que produziu mais galhos do que lenho, onde dos $42,8 \%$ de biomassa da copa, $36,5 \%$ foi de galhos devido ao elevado número de bifurcações e galhos, característica comum desta espécie.

As diferenças na produção de biomassa entre as duas espécies podem estar relacionadas com os fatores ambientais e fatores próprios inerentes à planta, condições edafoclimáticas, potencial genético de cada espécie para fixar carbono e absorver água e nutrientes e características ecofisiológicas das espécies. Florestas sob as mesmas condições edafoclimáticas apresentam, segundo Brown et al. (1994) diferenças na produção de biomassa. Alguns estudos relacionam a produção com os fatores climáticos, mas poucos estudos relacionam a produção com os fatores do sítio (Lugo, Brown; Chapman, 1988).

Diversos trabalhos mostram que o maior percentual de biomassa em uma espécie florestal encontra-se no fuste (madeira + 
casca). Isso independe da espécie (Drumond et al. 1997a; 1997b), espaçamentos e idade (Ladeira et al., 2001), do sítio (Baggio, 1994) e da procedência (Neves, Reissmann; Dünisch, 2001). Tal constatação também foi observada em M. ferruginea e M. umbellata (tab. 1).

Tabela 1 Biomassa média e distribuição relativa (\%) entre os componentes de biomassa de M. ferruginea e M. umbellata

Table 1: Weight and percentage (\%) of M. ferruginea and M. umbellata biomass components

\begin{tabular}{|c|c|c|c|c|c|c|}
\hline \multirow{3}{*}{$\begin{array}{l}\text { M. ferruginea } \\
\text { Total }^{(1)}\end{array}$} & \multicolumn{6}{|c|}{ Componente da biomassa } \\
\hline & $\begin{array}{l}\text { Madeira } \\
\text { do fuste }\end{array}$ & Casca & Galhos & Folhas & \multicolumn{2}{|c|}{ Miscelânea } \\
\hline & \begin{tabular}{l|l}
694,8 & $41,7 \%$
\end{tabular} & 158,1 & $46,4 \%$ & $2,1 \%$ & 4,7 & $0,3 \%$ \\
\hline Total ${ }^{(2)}$ & $2.412,3$ & 548,9 & $2.683,0$ & 124,3 & \multicolumn{2}{|c|}{16,1} \\
\hline Média ${ }^{(3)}$ & 69,5 & 15,8 & 77,3 & 3,6 & \multicolumn{2}{|c|}{0,5} \\
\hline Desvio Padrão & 84,7 & 16,7 & 95,9 & 2,8 & \multicolumn{2}{|c|}{0,7} \\
\hline Variância & $7.180,5$ & 279,4 & $9.197,3$ & 7,6 & \multicolumn{2}{|c|}{0,5} \\
\hline $\mathrm{CV}(\%)$ & 122,0 & 105,7 & 124,1 & 77,1 & \multicolumn{2}{|c|}{147,8} \\
\hline Total $^{(4)}$ & \multicolumn{3}{|c|}{$1.666,0$} & - & & \\
\hline Total lenhoso $^{(5)}$ & \multicolumn{3}{|c|}{$1.625,5$} & $97,6 \%{ }^{(6)}$ & & \\
\hline & \multicolumn{6}{|c|}{ Componente da biomassa } \\
\hline M. umbellata & $\begin{array}{l}\text { Madeira } \\
\text { do fuste }\end{array}$ & Casca & Galhos & Folhas & Mis & ânea \\
\hline Total $^{(1)}$ & \begin{tabular}{|l|l|}
438,2 & $42,1 \%$ \\
\end{tabular} & $6,8 \%$ & \begin{tabular}{l|l}
496,1 & $47,7 \%$
\end{tabular} & $3,2 \%$ & 2,0 & 0,2 \\
\hline Total $^{(2)}$ & $1.521,4$ & 247,5 & $1.722,5$ & 116,5 & & \\
\hline Média ${ }^{(3)}$ & 48,7 & 7,9 & 55,1 & 3,7 & & \\
\hline Desvio Padrão & 57,3 & 9,2 & 64,1 & 3,2 & & \\
\hline Variância & $3.277,7$ & 69,7 & $4.103,0$ & 10,2 & & \\
\hline CV $(\%)$ & 117,6 & 116,2 & 116,2 & 85,6 & & \\
\hline Total $^{(4)}$ & & $1.041,1$ & & - & & \\
\hline Total lenhoso ${ }^{(5)}$ & & $1.005,5$ & & $96,6 \%$ & & \\
\hline
\end{tabular}

A distribuição relativa dos componentes da biomassa das duas espécies seguiu a seguinte ordem decrescente, conforme pode ser observado na tabela 1: galhos $>$ madeira do fuste $>$ casca $>$ folhas $>$ miscelânea. $\mathrm{O}$ padrão da distribuição relativa da biomassa dos componentes dessas duas espécies da Floresta Ombrófila Mista Montana diferiu de outras espécies de florestas naturais como, por exemplo, os componentes arbóreos da mata natural, na região média do Rio Doce, Minas Gerais (Drumond et al., 1997a). Isso pode ser decorrente de diferentes metodologias de amostragem ou de diferenças relativas à fisionomia das espécies estudadas.

\section{Teores e Conteúdos de Macronutrientes}

No geral, os teores não foram uniformes entre as duas espécies. Para ambas espécies e para todos os componentes da biomassa, os teores de $\mathrm{N}$ foram maiores em relação aos teores de $\mathrm{P}$. O N apresentou os maiores teores em quase todos os componentes da biomassa, exceto na madeira do fuste casca e galhos que os teores de $\mathrm{K}$ foram maiores que os de $\mathrm{N}$ para as duas espécies. Os teores de $\mathrm{K}$ foram maiores em relação aos teores de $\mathrm{Ca}$ para todos os componentes da biomassa, exceto em $\mathrm{M}$. ferruginea, onde os teores de $\mathrm{K}$ foram menores em relação aos teores de $\mathrm{Ca}$ na casca e M. umbellata, que apresentou os teores de $\mathrm{K}$ menores em relação aos teores de $\mathrm{Ca}$ nas folhas, casca e galhos (tab. 2). 
Tabela 2 Teores $\left(\mathrm{g}_{\mathrm{kg}}{ }^{-1}\right)$ e conteúdos médios de macronutrientes $\left(\mathrm{kg}\right.$.especie $\left.{ }^{-1}\right)$ nos componentes de biomassa de $M$. ferruginea e $M$. umbellata

Table 2: Macronutrient content (g.kg-1) and weight (kg.species-1) in the biomass components of M. ferruginea and M. umbellata

\begin{tabular}{|c|c|c|c|c|c|c|c|c|c|c|c|c|}
\hline \multirow{3}{*}{ Componente } & \multicolumn{12}{|c|}{ Teor } \\
\hline & \multicolumn{6}{|c|}{ M. ferruginea } & \multicolumn{6}{|c|}{ M. umbellata } \\
\hline & $\mathrm{N}$ & $\mathrm{P}$ & $\mathrm{K}$ & $\mathrm{Ca}$ & $\mathrm{Mg}$ & $\mathrm{S}$ & $\mathrm{N}$ & $\mathrm{P}$ & $\mathrm{K}$ & $\mathrm{Ca}$ & $\mathrm{Mg}$ & $\mathrm{S}$ \\
\hline \multirow{5}{*}{$\begin{array}{l}\text { Folhas } \\
\text { Madeira do } \\
\text { fuste } \\
\text { Casca } \\
\text { Galhos } \\
\text { Miscelânea } \\
\end{array}$} & 24,63 & 1,90 & 15,00 & 8,23 & 1,40 & 2,46 & 14,04 & 0,91 & 9,66 & 9,80 & 2,60 & 2,05 \\
\hline & 2,74 & 0,13 & 6,96 & 2,24 & 0,23 & 2,99 & 2,41 & 0,58 & 6,47 & 4,89 & 0,33 & 0,37 \\
\hline & 8,13 & 0,52 & 9,45 & 13,44 & 0,67 & 2,17 & 4,34 & 0,37 & 6,03 & 29,04 & 1,10 & 0,87 \\
\hline & 6,61 & 0,59 & 9,59 & 7,00 & 0,55 & 1,99 & 3,97 & 0,24 & 7,03 & 8,08 & 0,79 & 1,19 \\
\hline & 12,10 & 8,40 & 8,40 & 6,19 & 1,15 & 2,64 & 14,55 & 8,78 & 8,78 & 7,80 & 2,45 & 1,96 \\
\hline \multirow{3}{*}{ Componente } & \multicolumn{12}{|c|}{ Conteúdo } \\
\hline & \multicolumn{12}{|c|}{ M. ferruginea } \\
\hline & \multicolumn{2}{|c|}{$\mathrm{N}$} & \multicolumn{2}{|c|}{$\mathrm{P}$} & \multicolumn{2}{|c|}{$\mathrm{K}$} & \multicolumn{2}{|l|}{$\mathrm{Ca}$} & \multicolumn{2}{|c|}{$\mathrm{Mg}$} & \multicolumn{2}{|c|}{$\mathrm{S}$} \\
\hline \multirow{2}{*}{$\begin{array}{l}\text { Folhas } \\
\text { Madeira do } \\
\text { fuste }\end{array}$} & \multicolumn{2}{|c|}{0,749} & \multicolumn{2}{|c|}{0,058} & \multicolumn{2}{|c|}{0,250} & \multicolumn{2}{|l|}{0,250} & \multicolumn{2}{|c|}{0,043} & \multicolumn{2}{|c|}{0,075} \\
\hline & \multicolumn{2}{|c|}{1,828} & \multicolumn{2}{|c|}{0,087} & \multicolumn{2}{|c|}{4,644} & \multicolumn{2}{|l|}{1,495} & \multicolumn{2}{|c|}{0,150} & \multicolumn{2}{|c|}{1,992} \\
\hline Casca & \multicolumn{2}{|c|}{1,232} & \multicolumn{2}{|c|}{0,079} & & 32 & 2,036 & & 0,1 & & & \\
\hline Galhos & 4,8 & & & & & 94 & 5,107 & & 0,4 & & & \\
\hline Miscelânea & 0, & & & & & 37 & 0,027 & & 0,0 & & & \\
\hline Lenhoso & 7,8 & & & & & 069 & 8,637 & & 0,6 & & & \\
\hline Total & 8, & & & & & 562 & 8,914 & & 0,7 & & & \\
\hline Comnonente & & & & & & M. un & ellata & & & & & \\
\hline Compontite & 1 & & & & & & $\mathrm{Ca}$ & & $\mathrm{M}$ & & & \\
\hline Folhas & 0, & & & & & & 0,318 & & 0,0 & & & \\
\hline $\begin{array}{l}\text { Madeira do } \\
\text { fuste }\end{array}$ & 1, & & & & & & 2,091 & & 0,1 & & & \\
\hline Casca & 0, & & & & & & 2,027 & & 0,0 & & & \\
\hline Galhos & & & & & & & 3,916 & & 0,3 & & & \\
\hline Miscelânea & 0, & & & & & & 0,015 & & 0,0 & & & \\
\hline Lenhoso & 3, & & & & & & 8,034 & & 0,6 & & & \\
\hline Total & 3, & & & & & 17 & 8,367 & & 0,6 & & & \\
\hline
\end{tabular}

As folhas das espécies $M$. ferruginea e M. umbellata apresentaram os maiores teores de alguns macronutrientes em relação aos outros componentes da biomassa. Isso porque os teores dos nutrientes são maiores nas partes mais ativas metabolicamente das plantas, como folhas e brotações, devido ao seu ativo envolvimento em reações enzimáticas e compostos bioquímicos de transferência de energia e transporte eletrônico (Gonçalves; Mello, 2000). As folhas possuem uma capacidade fotossintética altamente correlacionada com os teores dos nutrientes, especialmente com o N (Vitousek; Sanford, 1986). $M$. ferruginea apresentou maiores teores de $\mathrm{P}$ e $\mathrm{S}$ na miscelânea e $M$. umbellata os maiores teores de $\mathrm{N}$ e $\mathrm{P}$ na miscelânea.

Os teores mais elevados de alguns nutrientes nas folhas, em relação aos outros componentes da biomassa, tornam as folhas 0 componente com potencial para ciclagem de nutrientes, embora represente um pequeno percentual em relação à biomassa total das árvores (tab. 1).

Analisando os teores de $\mathrm{Ca}$ na casca (tab. 2), foi observado que os maiores teores foram verificados em $M$. umbellata, ou seja, mais que o dobro em relação a $M$. ferruginea. Os teores de $\mathrm{Ca}$ mais elevados na casca das espécies em relação aos outros componentes foram devidos, o $\mathrm{Ca}$ estar associado à parede celular, não sendo redistribuído, ocorrendo a diminuição do teor com o desenvolvimento da planta (Lambers, Chapin III; Pons, 2000).

A tabela 2 mostra que independentemente da espécie, os conteúdos de macronutrientes na biomassa, em valores absolutos, foram maiores na biomassa lenhosa (biomassa de madeira do fuste + casca + 
galhos). No que diz respeito aos conteúdos da biomassa total (madeira do fuste + casca + galhos + folhas + miscelânea) da $\mathrm{M}$. ferruginea a ordem decrescente foi: $\mathrm{K}>\mathrm{Ca}>\mathrm{N}>\mathrm{S}>\mathrm{Mg}$ $>\mathrm{P}$, no entanto, para $\mathrm{M}$. umbellata a ordem foi: $\mathrm{Ca}>\mathrm{K}>\mathrm{N}>\mathrm{S}>\mathrm{Mg}>\mathrm{P}$.

Tanto M. ferruginea como $\mathrm{M}$. umbellata apresentaram conteúdos médios semelhantes de $\mathrm{Ca}$ e $\mathrm{Mg}$ na biomassa total. Porém, M. ferruginea apresentou maiores conteúdos de $\mathrm{N}, \mathrm{K}$ e $\mathrm{S}$ na biomassa total, ou seja, principalmente para $\mathrm{N}$ e $\mathrm{K}$ que foram praticamente o dobro quando comparado com a $M$. umbellata. Nesse contexto, pode-se observar na tabela 2, que os conteúdos de $\mathrm{N}$ e $\mathrm{K}$ nos galhos de $M$. ferruginea foram o dobro em relação a $M$. umbellata e os conteúdos de $\mathrm{S}$ na casca de $M$. ferruginea foram muito mais que e o dobro em relação a $M$. umbellata.

O conteúdo de nutrientes é conseqüência de seus teores e da proporção de biomassa. Esse é um dos motivos pelos quais as espécies estudadas apresentaram diferenças nos conteúdos de macronutrientes. No entanto, por isso, a grande heterogeneidade do material em estudo quanto ao crescimento, compartimentalização da biomassa e outras características distintas levaram as espécies a acumularem diferentes quantidades de nutrientes.

\section{CONCLUSÕES}

- A produção de biomassa total, de casca e de galhos de $M$. ferruginea, em média, foi $37,5 \%, \quad 54,9 \%$ e $35,8 \%$, respectivamente superiores a de M. umbellata.

- Na produção de biomassa total de ambas espécies, os maiores conteúdos foram de $\mathrm{Ca} \mathrm{e}$ $\mathrm{K}$ e os menores de $\mathrm{Mg}$ e $\mathrm{P}$.

\section{REFERÊNCIAS}

BAGGIO, A. J. Estudio sobre el sistema agroforestal tradicional de la bracatinga (Mimosa scabrella Benth.) en Brasil: Productividad, manejo de residuos y elaboracion de compost. Madrid, 1994. 242f. Tese (Doutorado) - Universidade Politecnica de Madrid: Escuela Tecnica Superior de Ingenieros de Montes.
BOLETIM DE PESQUISA, Levantamento de reconhecimento dos solos do Estado do Paraná. Londrina: n. 27, t. 1 e 2, 1984.

BROWN, S. et al. Soil biological process in tropical ecosystems. In: WOOMER, P.L.; SWIFT, M.J. (Ed.) The biological management of tropical soil fertility. New York: John Wiley \& Sons Inc., 1994. p. 15-46.

CALDEIRA, M. V. W. Quantificação da biomassa e do conteúdo de nutrientes em diferentes procedências de Acácia-negra (Acacia mearnsii De Wild.). Santa Maria, RS. 1998. 96f. Dissertação (Mestrado em Engenharia Florestal) - Curso de PósGraduação em Engenharia Florestal, Universidade Federal de Santa Maria.

CALDENTEY, J. Acumulacion de biomassa em rodales naturales de Nothofagus pumulio em tierra Del fuego, Chile. Investigación Agrária Sistemas y Recursos Forestales, Madrid, v. 4, n. 2, p. 165-175, 1995.

DRUMOND, M. A. et al. Composição mineral e demanda nutricional de espécies florestais da Mata Atlântica. Revista Árvore, Viçosa, MG, v. 21, n. 1, p. 1-10, 1997a.

DRUMOND, M. A. et al. Distribuição de biomassa e de nutrientes em diferentes coberturas florestais e pastagem na região do médio Rio Doce-MG. Revista Árvore, MG, v. 21, n. 2, p. 187-199, 1997 b.

DRUMOND, M. A. Produção e distribuição de biomassa de alguma espécies arbóreas de uso múltiplo em solos de baixa fertilidade na região semi-árida do nordeste brasileiro. FERTBIO 98: interrelação fertilidade, biologia do solo e nutrição de plantas: consolidando um paradigma, 1998, Caxambu. Resumos... Caxambu: UFLA, 1998. p. 678.

EMBRAPA. Centro Nacional de Pesquisa de Solos. Sistema brasileiro de classificação de solos. Rio de Janeiro: Embrapa Solos, 1999. 412p.

GONÇALVES, J. L. M.; MELLO, S. L. M. O sistema radicular das árvores. In: GONÇALVES, J.L.M.; BENEDETTI, V. (Ed.) Nutrição e fertilização florestal. Piracicaba: ESALQ/USP, 2000. p. 221-267. 
IAPAR. Cartas climáticas básicas do Estado do Paraná. Londrina, 1994. 49p. (Documentos; 18).

IBGE. Manual técnico da vegetação brasileira. Rio de Janeiro, 1992. 92p.

LADEIRA, B. C. et al. Produção de biomassa de eucalipto sob três espaçamentos, em uma seqüência de idade. Revista Árvore, Viçosa, MG, v. 25, n. 1, p. 69-78, 2001.

LAMBERS, H.; CHAPIN III, F. S.; PONS, T. L. Plant physiological ecology. New York: Springer-Verlag, 2000. 540p.

LUGO, A. E.; BROWN, S.;CHAPMAN, J. An analytical review of production rates and stem wood biomass of tropical forest plantations. Forest Ecology and Management, Amsterdam, v. 23, p. 179-200, 1988.

LUY, A.; GOYA, J. F.; FRANGI, J. L. Distribución de la biomasa aérea y subterránea en plantaciones de Eucalyptus grandis de distintas edades en la región de Concordia, Entre Ríos (Argentina). In: Congreso forestal Argentino y latino - amaricano "Forestar y crecer", 2., 1997. Misiones. Actas... Misiones: Asociación Forestal Argentina, 1997.

MIYAZAWA, M. et al. Análises químicas de tecido vegetal. In: SILVA, F.C. (Ed). Manual de análises químicas de solos, plantas e fertilizantes. Brasília: Embrapa Slos, 1999. (Comunicação para Transferência de Tecnologia) p. 171-223.

MONTAGNINI, F.; SANCHO, F. Aboveground biomass and nutrient in young plantations of indigenous trees: implications for site nutrient conservation. Journal of Sustainable Forestry, New York, v. 1, n. 4, p. 115-139, 1994.
NEVES, E. J. M.; REISSMANN, C. B.; DÜNISCH, O. Biomassa e conteúdo de elementos minerais nos compartimentos arbóreos de Ceiba pentandra (L.) Gaertn. Boletim de Pesquisa Florestal, Colombo, n. 42, p. 41-49, 2001.

PARANÁ. Secretária de Estado de Agricultura e Abastecimento, Instituto de Terras, Cartografia e Florestas. Atlas do Estado do Paraná, Curitiba, 1987. 73p.

SILVA, J. F. Variabilidade genética em progênies de Eucalyptus camaldulensis Dehnh. e sua interação com espaçamento. Viçosa, 1990. 110f. Dissertação (Mestrado em Ciência Florestal) - Universidade Federal de Viçosa.

TEDESCO, M. J. et al. Análise de solos, plantas e outros materiais. Porto Alegre: UFRG, Departamento de Solos/Faculdade de Agronomia, 1995. 174p. (Boletim Técnico; 5).

VITOUSEK, P. M.; SANFORD, R. L. Nutrient cycling in moist tropical forest. Annual Review of Ecology and Systematics, Palo Alto, v. 17, p. 137-167, 1986.

WATZLAWICK, L. . Análise e estimativa de biomassa e carbono em floresta ombrófila mista e plantações florestais a partir de dados de imagens do satélite IKONOS II. Curitiba, [200-]. Tese (Doutorado em Ciências Florestais) - Setor de Ciências Agrárias, Universidade Federal do Paraná. 